\title{
QUALITY ANALYSIS OF HYDRAULIC SYSTEMS IN FUNCTION OF RELIABILITY THEORY
}

\author{
Orošnjak Marko, Jocanović Mitar \& Karanović Velibor, \\ University of Novi Sad, Faculty of Technical Sciences, Trg Dositeja Obradovića 6, Serbia
}
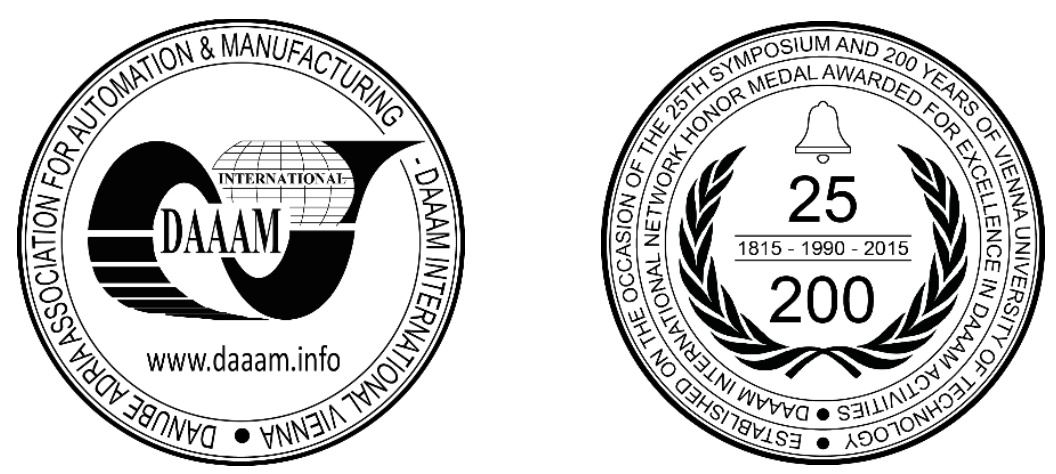

This Publication has to be referred as: Orosnjak, M[arko]; Jocanovic, M[itar] \& Karanovic, V[elibor] (2016). Quality Analysis of Hydraulic Systems in Function of Reliability Theory, Proceedings of the 27th DAAAM International Symposium, pp.0569-0577, B. Katalinic (Ed.), Published by DAAAM International, ISBN 978-3-902734-08-2, ISSN 1726-9679, Vienna, Austria

DOI: $10.2507 / 27$ th.daaam.proceedings.084

\begin{abstract}
Through design of a hydraulic systems various methods can be used for increasing system efficiency. Increasing efficiency while at the same time maintaining reliability and energy consumption is far from an easy task. In this article author have used mathematical and empirical evidence while trying to accomplish aforementioned. Design of hydraulic system is based on reliability theory and results are compared with the data collected from empirical sources and articles from previous research in the field. Based on simulation it is possible to increase efficiency of a hydraulic system either at design stage or during exploitation. Results from statistical modeling and simulation show that it is possible to improve system efficiency and therefore achieve higher overall system performance.
\end{abstract}

Keywords: Hydraulic system performance; efficiency; reliability modelling; maintenance; simulation

\section{Introduction}

Reliability theory is a science that studies the probability of failures in technical systems and their components (subsystems, set, subset, parts)[1]. Notion of reliability, generally, should be comprehend as the property of a system to operate without a failure in different environmental conditions and modes in a specific period $(t)$. Since authors are investigating design of a system based on reliability, much needed data is required. Therefore, it is a very complex task since, beside requiring large amount of statistical data on components, it also depends on other factors that influence operating conditions of a hydraulic system. Hence, reliability is driven by probability and statistics.

Hydraulic system is a core of control and power transmission. It is very imporant to design system properly or it can backfire with great losses to system overall. Therefore, it is very important to evaluate reliability of complex hydraulic system[2]. Many [2][3][4][5] have recognized the importance of reliability theory in hydraulic maintenance and design in order to improve overall system performance. Analysis of hydraulic system's operation indicates that reliability of a system and components depends on a large number of various factors, which are often interrelated in a complex manner. This factors can include: mechanical properties of components, material fatigue, loads, time in exploatation, oil degradation, contamination, maintenance, etc. Operating conditions have a significant role concerning reliability of a hydraulic component, which have been discussed by various researchers [4][6][7]. 
Beside aforementioned, similiar investigation concerning reliability of the hydraulic system design have been done in terms of impact that vibration has on a hydraulic pressure pipeline systems. It is claimed by the same authors that the research in terms of reliability of hydraulic components is still incomplete[8].

Some have used different tools and methods to investigate reliability of a failure for specific component in hydraulic system, such as FMEA. For example, Prado and de Souza [9] used Failure Modes and Effects Analysis (FMEA) for hydraulic system (hydraulic press) while aiming to define the critical components and the effects of their failures on the press performance.

Jocanović[7] studies the impact of changes of working parameters in hydraulic system (values of pressure, temperature and viscosity of hydraulic fluid to the number and size of solid particles that pass through the gap in the hydraulic component) and their impact on the reliability of components in the system. Karanović[6] studies the influence of microscale solid particles on the critical operational performances of the most common type of tribo-couples in power hydraulic components - directional valve. From results of experimental analysis by Karanović[6] it can be concluded that contamination has a great impact on system reliability and hydraulic component lifecycle.

Basic equations are used from [1][10] in order to calculate hydraulic system reliability in writing of this paper. Moreover, reliability of a system can be increased exclusively during the designing stage, while at every other lifecycle stage the reliability tends declining. The presented hydraulic model is used from [4] as a guideline example. While redesigning the system and tending to higher the overall mean operational time and reliability, results are far from panaceas but are slightly higher then previously designed model. Another thing to point out is that this example of the system is only used to higher the performance in terms of reliability.

\section{Hydraulic system with reliability data of components}

\subsection{Hydraulic system design}

Hydraulic system shown in figure 1. consist of a large group of components, which reliability (i.e. probabilty of failure) of components are given in table 1 . Working parameters of a system had been conducted within optimum range of $40^{\circ} \mathrm{C}$ to $60^{\circ} \mathrm{C}$. Reliability-wise all components have been connected serially, so in the case of a failure of any component the whole system stops. System is divided into three sub-systems: accumulation, extrusion and filling sub-system.

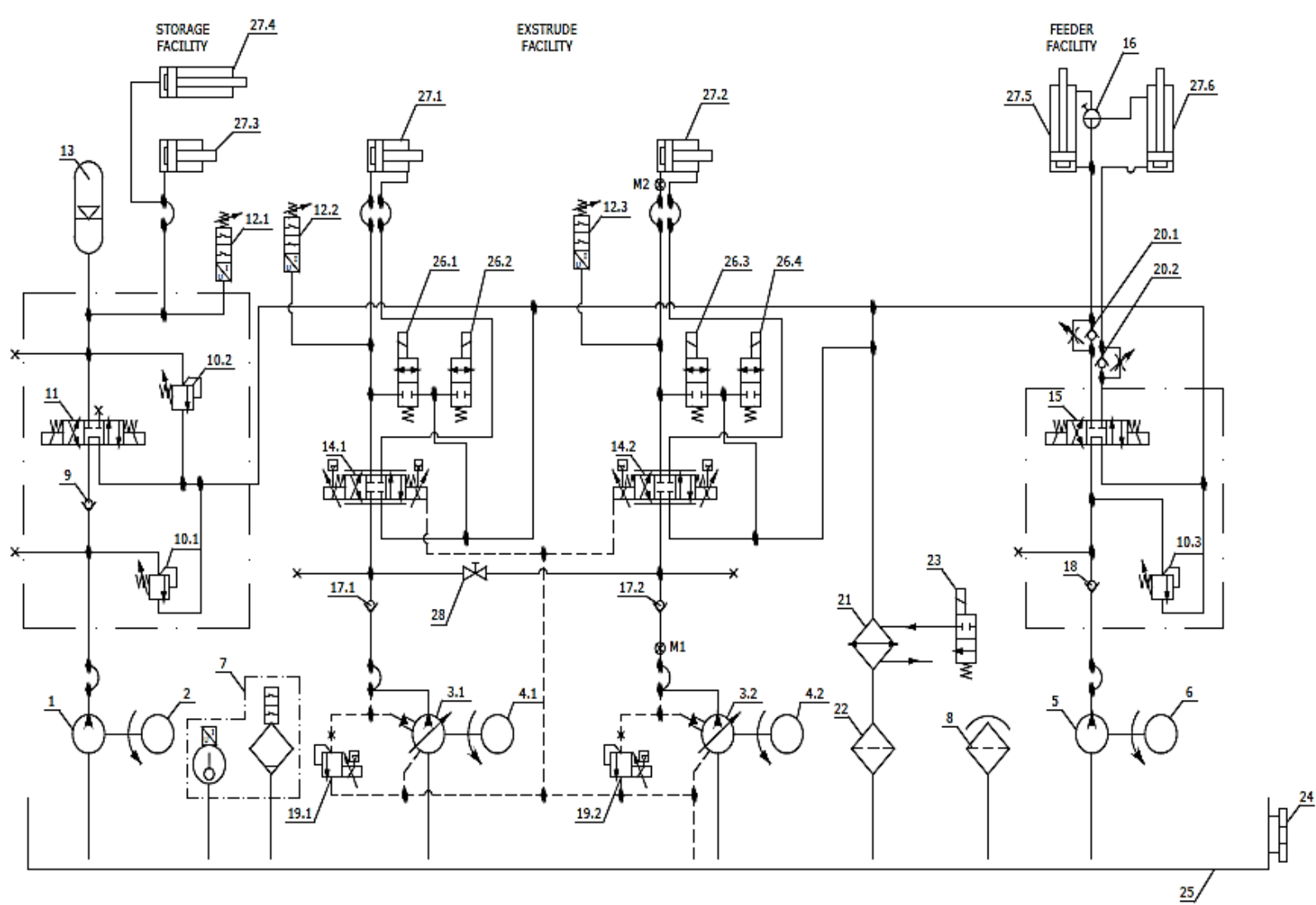

Fig. 1. Block diagram of the hydraulic system used for reliability-analysis-based component design[4] 
All data about component failures are based on data given by Fitch \& Hong[11]. In their investigation and results, they show the influence of different factors on the reliability of hydraulic components and they explicitly show this in their book. Based on their experiments they have defined the expected failure rates for each hydraulic system component. Therefore, based on the data given by Fitch \& Hong[11] it is possible to define the expected reliability each of the subsystem and also to calculate mean operating time and compare it with previous design in terms of performance. The failure rate (range and mean) values of all components in the system from figure 1 . are given in the table 1.

\begin{tabular}{|c|c|c|c|}
\hline \multirow{2}{*}{ Position } & \multirow{2}{*}{$\begin{array}{l}\text { Hydraulic component } \\
\text { (Failure Rate - marks) }\end{array}$} & \multicolumn{2}{|c|}{ Failure rate $\left(\mathrm{x10}^{-6}\right)$} \\
\hline & & Range of Value & Mean \\
\hline (1) & (2) & (3) & (4) \\
\hline$(1),(5)$ & Gear pump $\left(\lambda_{1}, \lambda_{5}\right)$ & & 13 \\
\hline$(1),(4.1),(4.2),(6)$ & Electrical motor $\left(\lambda_{2}, \lambda_{4}, \lambda_{6}\right)$ & 2 to 18 & 10 \\
\hline$(3.1),(3.2)$ & Axial piston pump $\left(\lambda_{3}\right)$ & 6 to 13 & 9 \\
\hline$(9),(17.1),(17.2),(18)$ & Check valve $\left(\lambda_{9}, \lambda_{17}, \lambda_{18}\right)$ & 0.112 to 10.2 & 6.5 \\
\hline$(10.1),(10.2),(10.3)$ & Relief valve $\left(\lambda_{10}\right)$ & 1.41 to 8.13 & 5.88 \\
\hline $\begin{array}{l}(11),(15),(23),(26.1), \\
(26.2),(26.3),(26.4)\end{array}$ & $\begin{array}{l}\text { Electro - hydraulic valve } \\
\left(\lambda_{11}, \lambda_{15}, \lambda_{23}, \lambda_{26}\right)\end{array}$ & 2.27 to 19.7 & 11 \\
\hline$(12.1),(12.2),(12.3)$ & Pressure switch $\left(\lambda_{12}\right)$ & & 10 \\
\hline (13) & $\begin{array}{l}\text { Gas charged accumulator } \\
\left(\lambda_{13}\right)\end{array}$ & 0.35 to 7.5 & 6.8 \\
\hline$(14.1),(14.2)$ & Proportional valve $\left(\lambda_{14}\right)$ & 16.8 to 56 & 30 \\
\hline$(16),(28)$ & Ball valve $\left(\lambda_{16}, \lambda_{28}\right)$ & 1.11 to 7.6 & 4.6 \\
\hline$(19.1),(19.2)$ & $\begin{array}{c}\text { Pressure compensated relief } \\
\text { valve }\left(\lambda_{19}\right)\end{array}$ & & 20 \\
\hline$(20.1),(20.2)$ & $\begin{array}{l}\text { Check valve }- \text { flow } \\
\text { restrictor }\left(\lambda_{20}\right)\end{array}$ & 0.112 to 10.2 & 6.5 \\
\hline$(21)$ & Radiator for cooling $\left(\lambda_{21}\right)$ & & 1 \\
\hline (22) & Filter $\left(\lambda_{22}\right)$ & 0.01 to 1.62 & 0.79 \\
\hline$(25)$ & Hydraulic reservoir $\left(\lambda_{28}\right)$ & 0.48 to 2.52 & 1.5 \\
\hline $\begin{array}{l}(27.1),(27.2),(27.3), \\
(27.4),(27.5),(27.6)\end{array}$ & Hydraulic cilinders $\left(\lambda_{27}\right)$ & & 0.008 \\
\hline \multicolumn{4}{|c|}{ Redesigned hydraulic system } \\
\hline$(29.1)(29.2)$ & $\begin{array}{l}\text { Gear pump with frequency } \\
\text { regulation }\left(\lambda_{27}\right)\end{array}$ & & 13 \\
\hline$(30.1)$ & $\begin{array}{c}\text { Relief valve - with relieve } \\
\text { of load valve }\left(\lambda_{30}\right)\end{array}$ & 0.224 to 14.1 & 5.7 \\
\hline$(31.1)(31.2)$ & $\begin{array}{l}\text { Electro - hydraulic valve } \\
\text { (directional control) }\end{array}$ & 1.81 to 7.22 & 4.6 \\
\hline
\end{tabular}

Table 1. Reliability of constituent components within the considered hydraulic system [4][11]

\subsection{Reliabiliy theory used as method in research}

Reliability is a tool that can be used in development and analysis of a hydraulic systems, from the selection of components to the planning of efficient maintenance routines[9]. Reliability is also characteristic of an item, generally designated by $\mathrm{R}(t)$, and expressed by the probability $\mathrm{P}(t)$ that the item will perform it's required function under given conditions for a stated time interval $(t)$. Considered qualitatively, reliability can also be defined as the ability of an item to remain functional. Hence, reliability specifies the probability that no operational interruptions will occur during a stated time interval $(t)$ [10]. This does not exclusively reflect only the item or part of the system, but on a system as whole. Basic reason lies in the fact that complex system unites smaller or/and bigger parts of constituent elements (sub-system, assemblies, sub-assemblies, parts) and it can not be judged if one doesnt analyze and analytically cover reliability of each element respectively[1]. Another thing to point out is that in reliability bond diagrams (RBD) components and their bonds are specifically analyzed from reliability standpoint. 
Ways to connect parts (components) into system are divided into:

- serial

- parallel

- pasive parallel

- partial parallel

- $\quad$ special (quazy-serial, quazy-parallel)

- complex (combinaton of these bonds elements)

Analysis of a system's reliability has been conducted under assumption that is working under period of random failures. Reliability of a system can be described with exponential distribution law and it is expressed with equation:

$$
R(t)=e^{-\lambda \cdot t}
$$

where $R$ is system reliability, $\lambda$ is system failure rate (for the exponential distribution function, failure rate is constant or nearly constant value), $t$ is system operational time.

Reliability of a system arranged in serial order:

$$
R(t)=R_{1}(t) \cdot R_{2}(t) \cdots R_{n-1}(t) \cdot R_{n}(t)=\prod_{i=1}^{n} R_{i}(t)
$$

Substituting equation (1) into equation (2):

$$
R(t)=e^{-\lambda_{1} \cdot t} \cdot e^{-\lambda_{2} \cdot t} \cdots e^{-\lambda_{n-1} \cdot t} \cdot e^{-\lambda_{n} \cdot t}=e^{-\left(\sum_{i}^{n}=0 \lambda_{i}\right) \cdot t}
$$

While calculating the reliability using eq.(3) of the sub-systems in time interval taken from range of values: 1, 2, 3, 6, 9, 12, 18, 24, 30, 36 months, Jocanović et al. [4] came with results of each sub-system from one month: a) Filling subsystem $R(730)=0.957$; b) Extrusion sub-system $R(730)=0.781$; c) Accumulation sub-system $R(730)=0.976$. Total reliability of the system had been calculated and charted (figure 2) and results clearly showed that extrusion sub-system was the least reliable within the system and components with failure rates $\lambda_{3}, \lambda_{14}, \lambda_{19}$, i.e. axial piston pump, proportional valve and pressure compensated relief valve were replaced. Calculated mean operational time was:

$$
T_{o p}=\frac{1}{\lambda}=2268.96 h
$$

which was pretty low comparing to a final redesigned system.

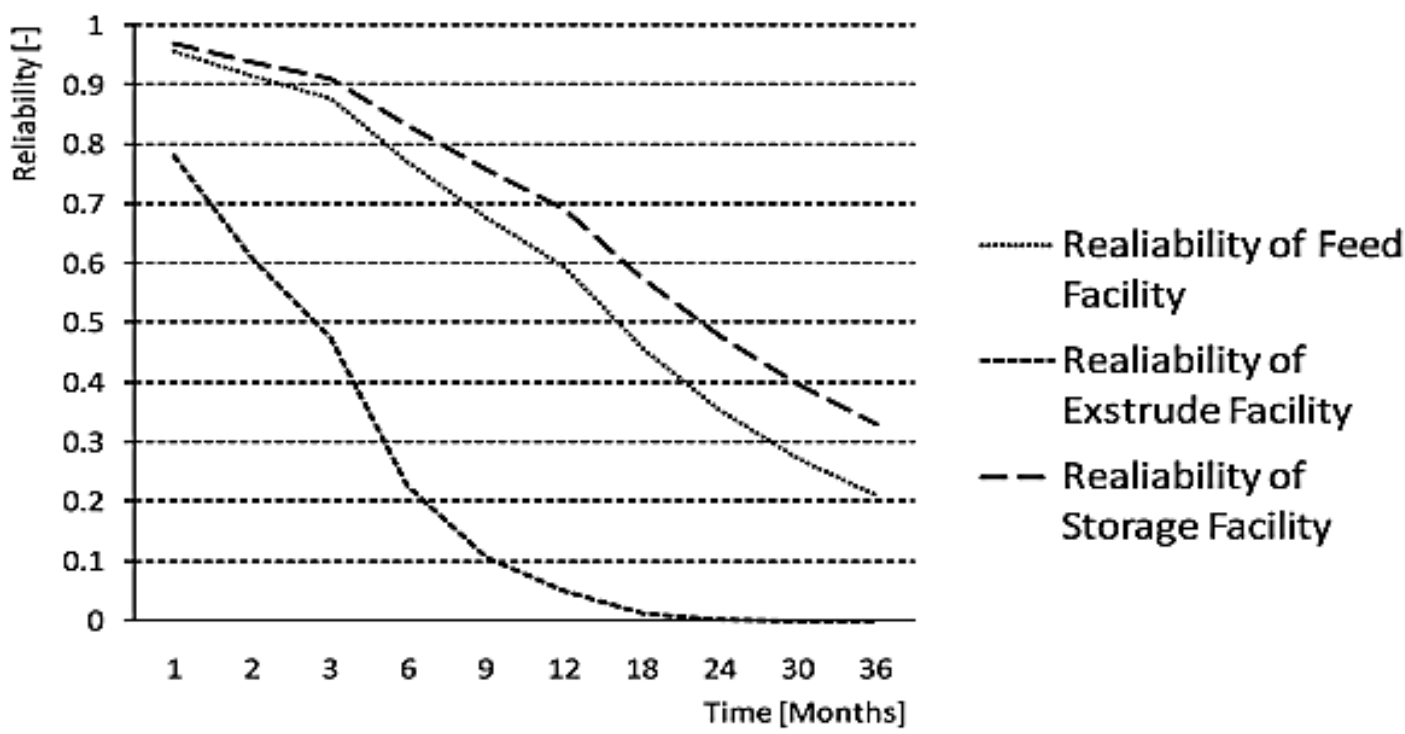

Fig. 2. Total reliability of the three sub-systems of considered hydraulic system 


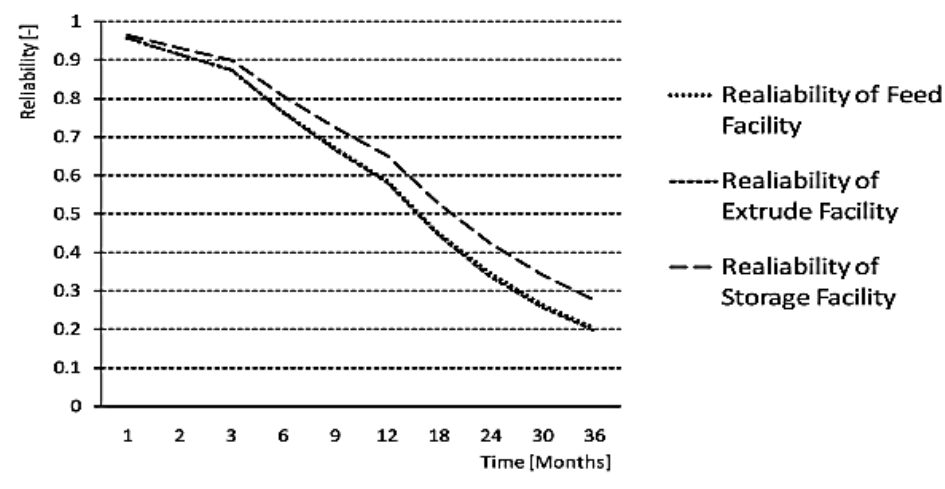

Fig. 3. Total reliability of redesigned hydraulic system in [4]

Even so, system was still failing every 2 hours due to overheating. While monitoring the system it was noticed that the biggest problem was oscilations in pressure and flow and they were the main cause of temperature rise and overheating. Investigation showed that it was problem in hydraulic system design. Axial piston pump is replaced with gear pump with frequency regulation, proportional valve is replaced with internal pressure relief valve, while proportional distributing valve was substituted with electro-hydraulic valve. Newly designed system compared to original system showed $17,43 \%$ reliability gain, while mean operational time for the system was $T_{o p}=5811,99 \mathrm{~h}$, i.e. increase of $156 \%$.

The authors of this paper investigated further and came with a conclusion that it is possible to higher the effectivness of the system even more but at the higher cost and energy consumption. This can be done by proposing new design of a system but insted of two main pumps in extruder facility only one pump with higher capacity and power will be used in the system as a main and the other will be there as a passive element, i.e. if main one fails.

\section{Newly proposed hydraulic system with higher reliability}

Basic idea and goal was to higher the effectiveness of the hydraulic system without adding new elements which can affect reliability overall. New model is represented in figure 4. Based on the model given in figure 4. it is obvious that some components are replaced and others separated from the system. These components were mainly in extrusion subsystem: the axial piston pumps (3.1)(3.2) have been replaced with gear pumps (29.1)(29.2) with frequency regulator. Proportional valves (14.1)(14.2) had been replaced with electro-hydraulic distribution valve (31.1)(31.2), while electrohydraulic valves (26) had been removed from the system. Notice that extruder facility is now driven by main gear pump (29.1) instead of both working separately. The idea was to use gear pump (29.1) as a main pump while the other gear pump (29.2) will work as a passive component to higher the reliability rate of the system as a whole, since the effectiveness of the extruder sub-system was the lowest.

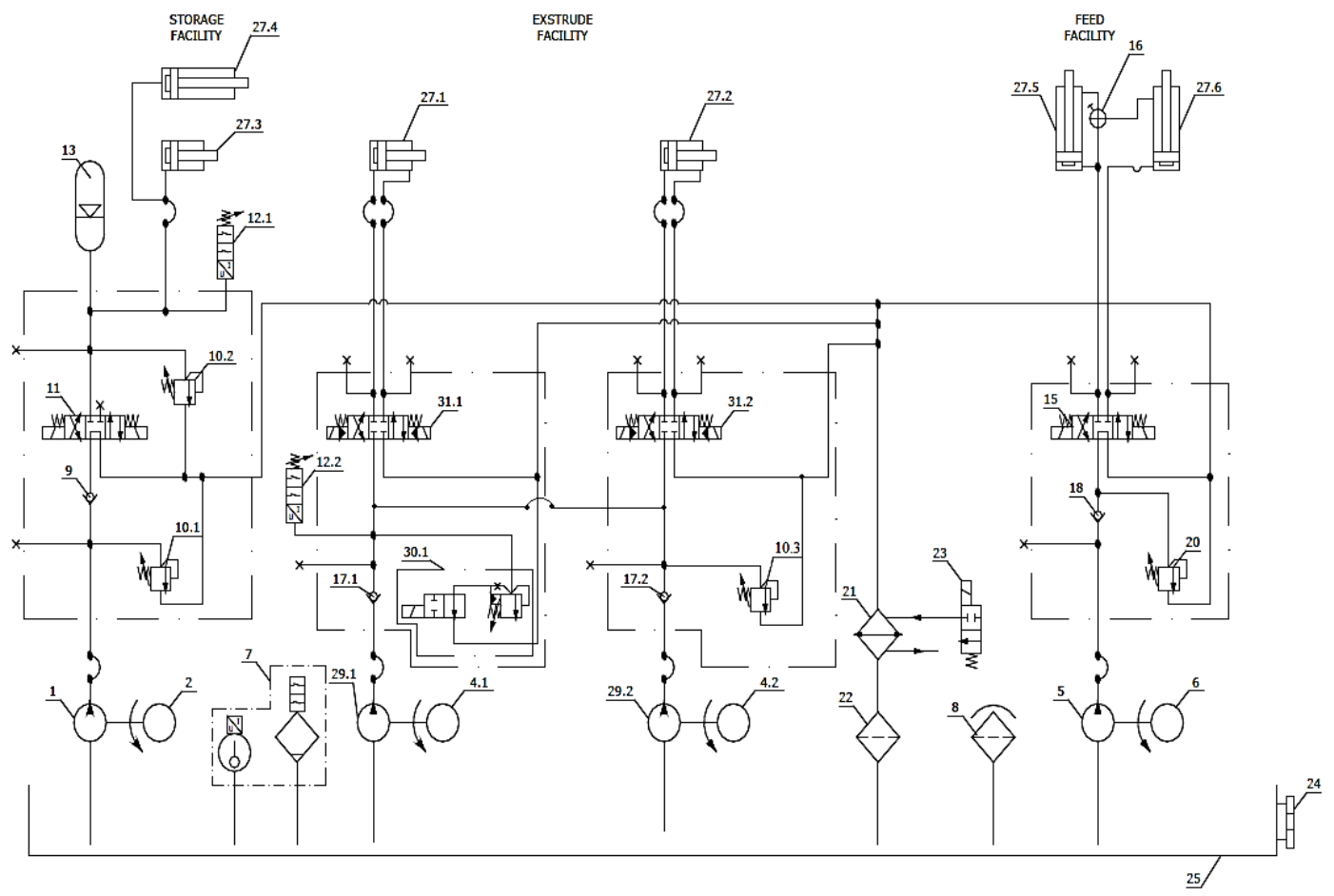

Fig. 4. New block diagram concept of improved hydraulic system 
Hydraulic system presented in figure 1 is used for reliability analysis of components. Since, the basic calculations are done by the exponential distribution of serially connected components in the system, the reliability was: a) Filling subsystem $R(730)=0.957$; b) Extrusion sub-system $R(730)=0.781$; c) Accumulation sub-system $R(730)=0.976$. Newly proposed hydraulic system for reliability based analysis showed following results: a) Filling sub-system $R(730)=0.951$; b) Extrusion sub-system $R(730)=0.977$; c) Accumulation sub-system $R(730)=0.954$. Changes in reliability were twofold. Failure rates $(\lambda)$ in this paper were used by only mean values to calcuate reliability and mean operational time. Second, redesigning system, replacing and removing some components and also using parallel passive connection between components extruder sub-system showed significant improvement in reliability, as system itself.

One of the main reasons to replace axial piston pumps lies in the fact that system doesnt require pressure and flow regulations but rather a constant flow to actuators. Even so, replacing axial piston pump with gear pump is possible with decently high overall performance of gear pump. Lately, gear pumps are constructed and designed with quiet operation and low pulsations even at high speeds and resemble with high volumetric efficiency. This is done by avoiding entrapment between the teeth by using redesigned inclined teeth[12].

Another thing to point out is that proportional valve in opposite to electro-hydraulic valve require higher level of fluid cleanness. Particulate contaminant in the system containing directional control valve can be most cripling substance[13] and in the case of proportional valve demands are even higher. Contaminats in the fluid (especially solid particles) can cause large amount of damage to proportional valves which are very sensitive[14]. Proportional valve has a first stage, a hydraulic amplifier (converts an electrical input to a hydraulic control pressure), and a second stage (which responds to the control pressure and meters an accurate output flow). Hence, several failure modes can occur in the first stage such as ferrous particles that are attracted to magnetic field and cause a large hysteresis. Contaminant lock is the major failure in second stage, since any contaminant can lodge in the clearance and silt up the spool[13]. Therefore the biggest threat to proportional valves by particle contamination is sliding wear and erosion[15] which directly lead to higher system energy consumption, cost, maintenance, time and lower reliability most of all. In order to cope with the obstacle different types of methods can be used[6][16]. Usually using different types of filters and places of installation can help control contamination, but this leads to pressure drops, costs, etc[17]. The higher the fluid cleanness is required the higher are the expences of maintenance overall[18]. Since it was mentioned before that system suffered from overheating, next to particle contamination, heat is the second most common cause of failure of hydraulic components[19][20]. In order to overcome that it needs to be controlled, elseway oil will degrade if working temperature gets to high and therefore viscosity will get lower. Hence, getting viscosity critically low it no longer maintains a boundary lubrication. Therefore, it can lead to rise in component surface temperatures, and subsequent mechanical failures of components. For example, number of helicopter accidents have been caused due to loss of lubrication[21].

Redesigning hydraulic system will be accomplished by the use of reliability bonds. As said, the goal is to increase reliability of the extruder subsystem. This can be done by installation of a passive gear pump which turns on if the main one fails. It is obvious that this leads to higher start up costs for redesigning but it will also increase mean operational time. Therefore, to justify costs of investment it would be interesting to conduct a research of cost-effectivness in this type of solution. Hydraulic system can be represented in block diagrams of reliability (RBD)[10]. For (a) filling subsystem and (c) accumulation sub-system the blocks are serial connected and calculated by eq.(3) and in this case they were not illustrated. While (b) extrusion sub-system is represented in figure 5 . for better apprehension.

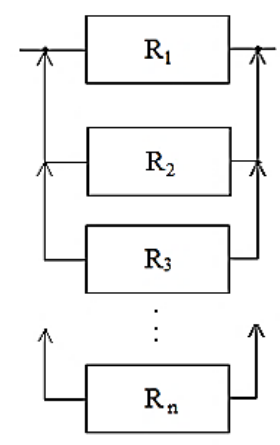

Fig. 5. Passive parallel connection

The RBD in figure 5. does not represent simply parallel connection but a passive parallel connection. Under the passive parallel connection or passive reserve, means that the installation of a passive component $\left(R_{2}, R_{3} \ldots R_{n}\right)$ replaces main component, so that component inclusion in the work is achieved only if an active (main) component fails or needs to be supported. Therefore, the idea was to use the gear pump (29.1) as a main component while gear pump (29.2) acts as a passive element. Calculation for passive parallel connection can be done by Poisson distribution:

$$
R(t)=\sum_{k=0}^{n} \frac{(\lambda t)^{k}}{k !} e^{-\lambda \cdot t}=\left\lfloor\frac{(\lambda t)^{0}}{0 !}+\frac{(\lambda t)^{1}}{1 !} \frac{(\lambda t)^{2}}{2 !} \cdots \frac{(\lambda t)^{n}}{n !}\right\rfloor e^{-\lambda \cdot t}
$$


where is:

$n$ - number of reserve components (elements) in the system;

$k-0 \div \mathrm{n}-$ variable - number of elements in passive connection;

$\lambda$ - const. - intensity of failure exponential law of distribution;

$t$ - time variable.

Hence, only $R_{l}$ (fig 2.) presents active (main) component and the others $\left(R_{2}, R_{3} \ldots R_{n}\right)$ are there as passive component(s) to replace active component only if it fails, and in this particular case main goal is to include the auxiliary gear pump if the main gear pump fails. Therefore, particular hydraulic extruder sub-system is modelled as follows:

$$
\begin{aligned}
& R_{\text {active }}(t)=e^{-\lambda_{29} \cdot t} \cdot e^{-\lambda_{4} \cdot t} \cdot e^{-\lambda_{17} \cdot t} \cdot e^{-\lambda_{30} \cdot t} \cdot e^{-\lambda_{12} \cdot t} \cdot e^{-\lambda_{31.1} \cdot t} \cdot e^{-\lambda_{27.1} \cdot t} \cdot e^{-\lambda_{31.2} \cdot t} \cdot e^{-\lambda_{27.2} \cdot t} \\
& R_{\text {pasive }}(t)=e^{-\lambda_{29} \cdot t} \cdot e^{-\lambda_{4} \cdot t} \cdot e^{-\lambda_{17} \cdot t} \cdot e^{-\lambda_{10} \cdot t}
\end{aligned}
$$

Including eq. (7) and (6) into eq. (5):

$$
R_{\text {ex }-s y s}(t)=\sum_{k=1}^{1} \frac{(\lambda t)^{1}}{1 !} e^{-\lambda \cdot t}=\left\lfloor\frac{(\lambda t)^{0}}{0 !}+\frac{(\lambda t)^{1}}{1 !}\right\rfloor e^{-\lambda \cdot t}
$$

Calculations show the results of reliability for time $t=730 \mathrm{~h}$ ( 1 month) for 1 passive element as follows:

$$
\begin{aligned}
& R_{\text {ex-sys }}(t)=\sum_{k=1}^{1} \frac{(\lambda t)^{1}}{1 !} e^{-\lambda_{i} \cdot t} \\
& R_{\text {ex-sys }}(730)=\left\lfloor 1+\frac{\left(\lambda_{29}+\lambda_{4}+\lambda_{17}+\lambda_{10}\right) \cdot t^{1}}{1 !}\right\rfloor e^{-\left(\lambda_{29}+\lambda_{4}+\lambda_{17}+\lambda_{30}+\lambda_{12}+\lambda_{31}+\lambda_{27}+\lambda_{31}+\lambda_{27}+\lambda_{21}+\lambda_{22}+\lambda_{23}\right) \cdot t}
\end{aligned}
$$

The results are: a) Filling sub-system $R(730)=0,951$, b) Extrusion sub-system $R(730)=0,977$, c) Accumulation sub-system $R(730)=0,954$.

From research based on reliability theory on this particular hydraulic system it has been shown that most unreliable sub-system was extruder, i.e. least reliable assembly of the hydraulic system. For calculations of reliability of all subsystems, mean failure rates $(\lambda)$ were used. Results are presented in figure 6 . From originally designed hydraulic system reliability gain of $21,51 \%$ claims a significant improvement. Replaced and discarded components have led to increased reliability of the whole system. Another thing to point out is mean operational time. The results are as follows: $T_{o p}{ }^{\prime}=$ 6052,995 hours which also led to increase of $\sim 3800$ hours from $T_{o p}=2268,96$ hours originially designed and even more than 200 hours comparing to redesigned system in [4]. This indicates the increase of $167 \%$ and $4,15 \%$ from originally designed and redesigned by [4], respectivelly.

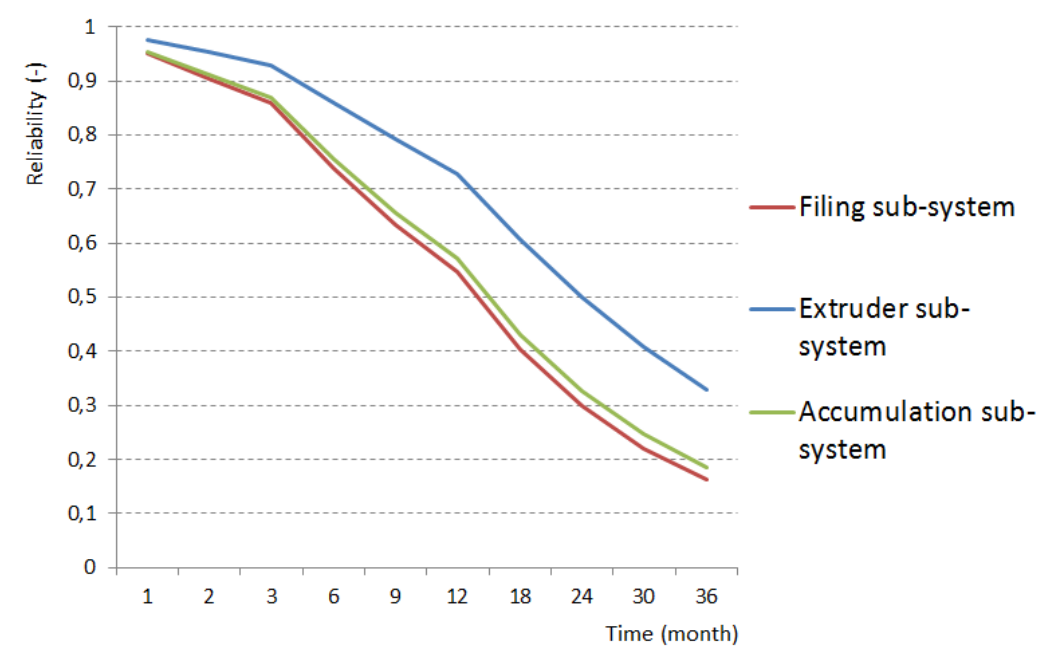

Fig. 6. Reliability of redesigned system 


\section{Conclusion and further research}

From investigation in the field of hydraulic system effectiveness very little research have been done concerning reliability analysis in conjuction with hydraulic systems. During research authors found considerable amount of reliability data in terms of technical systems[22] but most of them lack the research concerning hydraulic systems. Therefore scientific community should consider this as a potential field that lack the research data especially entering the new era of Industry 4.0 where reliability of automatic technical systems and components can be crucial.

Constant failures of a hydraulic system leads to high downtimes, expences, component failures, etc. Main objective was resolving the problem of low mean operational time of hydraulic system using reliability data of components and redesigning the system. From this article it has been shown that it possible to improve sub-system and system performance overall. The biggest problem was extruder sub-system with axial piston pump. It was realized that system works in a contaminated environment and gear pumps can handle contamination better than axial piston pump with targeted ISO cleanless level[23]. Another thing to point out is that system doesnt require pressure or flow regulations but rather a constant flow to actuators, therefore some of the components, i.e. proportional valve, is replaced with electrohydraulic valve.

It has been noticed that the extruder facility which is driven by main gear pump (29.1 at figure 4) now leads to twofold improvements. First, failure rates indicates higher mean operational time. Secondly, removing or replacing some components of extruder sub-system showed significant imrpovement in reliability. This could only be done by adding a passive parallel connection with a passive gear pump but also leads to higher investments and costs in system redesign. It can be improved even further but it needs to be conducted cost effective analysis while adding or replacing low/high reliable components. From discussion it can be realized that applying reliability on improving hydraulic system performanse can help identify down-time causes, weakest component/s, value of operating parameters, mean operational time, etc. It can improve maintenance by proactively monitoring reliability of a system in real-time, which can help predict and react to a potential failure.

Another interesting keymark that can be further researched are influence of solid particles, air and water influence on the reliability of a hydraulic system. Therefore, it would be interesting to see how does contaminants in the hydraulic oil influence effectiveness of a system which can be expressed in system reliability and even develop a model. Hence, investigation could go separate ways concerning system reliability in terms of hydraulic design based on the reliability of components and reliability modeling in terms of influence of contaminated oil. It must not be left out that highest reliability-performance can only be done at the system design so that must be duly noted. As for improving reliability based on contamination control it can surely contribute to a better system performance, understanding the failure, determining critical period of a contamination, critical points in reliability hysteresis, etc. Therefore, it represents a potential open field for discussion to scientific community.

\section{References}

[1] Ivanovic, G., Stanivukovic, D. \& Beker, I. (2010). Reliabilty of Technical Systems. FTN publish, Novi Sad. (written in Serbian). ISBN 978-86-7892-247-3

[2] Chen, D., Yao. C. \& Feng. Z. (2013). Reliability Prediction Method of Hydraulic System by Fuzzy Theory. $6^{\text {th }}$ IFAC Symposium on Mechatronic Systems. The international federation on Automatic Control. April 10-12. Hangzhou, China. Published by Elsevier Ltd. All rights reserved. pp 457-462. DOI: 10.3182/20130410-3-CN-2034.90001.

[3] Avontuur, G.C. \& van der Werff, K. (2002). System reliability analysis of mechanical and hydraulic drive systems. Reliability engineering and System safety. Vol. 77. Issue 2. pp.121-130. ISSN: 0951-8320

[4] Jocanović, M., Šević, D., Karanović, V., Beker, I. \& Dudić, S. (2012). Increased efficiency of Hydraulic Systems Through Reliability Theory and Monitoring of System Operating Parameters. Strojniški vestnik - Journal of mechanical engineering. Vol.58, Issue 4. pp.281-288. ISSN:0039-2480. DOI: 10.5545/sv-jme.2011.084

[5] Rahimdel, M. J., Ataei. M., Khalokakaei, R. \& Hoseini, S.H. (2013). Reliability based maintenance scheduling of hydraulic system of rotary drilling machines. International Journal of Mining Science and Technology. pp. 771-775. ISSN: 2095-2686. DOI: http://dx.doi.org/10.1016/j.ijmst.2013.08.023

[6] Karanović, V. (2015). Development of a solid particle influence model on performance of pistoncylinder contacting pairs for hydraulic components. Ph.D. Thesis. Department of Industrial Engineering and Management. Faculty of Technical Sciences, University of Novi Sad, Serbia, Novi Sad. Available at: http://nardus.mpn.gov.rs/bitstream/handle/123456789/1856/Disertacija.pdf?sequence=1\&isAllowed=y

[7] Jocanović, M. (2010). Approach to research and define the model for the calculation of flow of solid particles with a mass of mineral oil through the gaps in a function of the constructive operating parameters of hydraulic components. Ph.D. Thesis. Departman of Industrial Engineering and Management, Faculty of Technical Sciences, University of Novi Sad, Serbia, Novi Sad.

[8] Zhang, T. \& Liu, X. (2013). Reliability design for impact vibration of hydraulic pressure pipeline systems. Chinese Journal of Mechanical Engineering. Vol. 26. Issue 5. pp. 1050-1055. Available at: http://www.cjmenet.com/EN/Y2013/V26/I5/1 
[9] Prado, A. C. \& de Souza, G.F.M. (2003). Reliability analysis of hydraulic systems employed in presses: Application to deep drawing press for 250 ton. Proceedings of COBEM 2003. 17th International Congress of Mechanical Engineering. November 10-14. Sao Paolo. Brasil. Available at: http://www.abcm.org.br/anais/cobem/2003/html/pdf/COB03-0185.pdf

[10] Birolini, A. (2010). Reliability Engineering - Theory and Practice, $6^{\text {th }}$ ed., Springer, Berlin.

[11] Fitch, E.C. \& Hong, I.T. (2004). Hydraulic system design for service assurance, BarDyne, Inc., Stillwater.

[12] Opran, C., Pricop, M \& Teodoru, C. (2014). Embedded engineering for low noise gear pumps. DAAAM international scientific book 2014. Chapter 13. pp.163-170. ISSN 1726-9687. DOI: 10.2507/daaam.scibook.2014.13

[13] Fitch, E.C. (1988). Fluid Contamination Control. Oklahoma state University, Stillwater, Oklahoma, USA.

[14] Sasaki, A. (2001). Hydraulic valve problems caused by oil oxidation products. Hydraulic Failure Analysis: Fluids, Components, and System Effects. Authors: Totten, G.E., Wills, D.K., and Feldmann, D.G. ASTM West Conshohocken, USA. pp.474-488. DOI: 10.1520/STP38296S

[15] Stecki, J. (2009). Contamination control and failure analysis. Lubrication and Maintenance of Industrial Machinery: Best practicies and reliability. Editors: Gresham, R.M. and Totten, G.E. by Taylor and Francis Group, LLC. United States. pp IV-33. ISBN: 978-1-4200-8936-3 DOI: 10.1201/9781420089363.ch4

[16] Orošnjak, M. (2015). Indicator development for maintaining hydraulic systems based on tribological parameteres. UNS FTN - Proceedings Faculty of Technical Sciences, Novi Sad. Vol. 16. Issue 12. pp. 3025-3029. ISSN 0350428X. Available at: http://www.ftn.uns.ac.rs/2041336908/broj-16

[17] Savić, V. (1995). Energy consumption of different construction solution of hydraulic systems. Proceedings of HEP. Hydralics in Industry. Issue 1. May.1995.

[18] Savić, V. (2012). Oil Hydraulics 4 part 1: examples of hydraulic system calculations. IKOS, Novi Sad. Written in Serbian. ISBN 978-86-915541-0-1

[19] Savić, V. (1995). Tribology and Lubrication. FELJTON. Novi Sad. (written in Serbo-Croatian)

[20] Crosford, J. (2015). Industrial Reliability in Hydraulics. Fluidpower world. Available from: http://www.fluidpowerworld.com/industrial-reliability-in-hydraulics/ Accessed: 05.07.2016

[21] Rashid, H.S.J., Place, C.S., Mba, D., Keong, R.L.C., Healey, A., Kleine-Beek, W., \& Romano, M. (2015). Reliability model for helicopter main gearbox lubrication system using influence diagrams. Realiability Engineering \& System Safety. vol. 139. pp.50-57. ISSN: 0951-8320 DOI: http://dx.doi.org/10.1016/j.ress.2015.01.021

[22] Straka, L.; Rimar, M.; Corny, I. \& Mihalcova, J. (2011). Increasing of Operational Reliability of Technical System, Annals of DAAAM for 2011 \& Proceedings of the 22nd International DAAAM Symposium, 23-26th November 2011, Vienna, Austria, Volume 22, No. 1, ISSN 1726-9679, ISBN 978-3-901509-83-4, Katalinic, B. (Ed.), pp. 10891090, Published by DAAAM International Vienna, Vienna. Available at: http://www.daaam.info/Downloads/Pdfs/proceedings/proceedings_2011/1089_Straka.pdf

[23] Understanding ISO codes Available (n.d.). https://www.hyprofiltration.com/clientuploads/directory/Knowledge/PDFs/ISO\%20Intro.pdf Accessed: 09.09.2015 